\title{
review
}

\section{Abdominal Compartment Syndrome}

\author{
Robert B. Sanda
}

From the Department of Surgery, Hail General Hospital, Hail, Saudi Arabia

Correspondence: Robert B. Sanda, MBBS, FRCSI, Department of Surgery, Hail General Hospital, Hail 81451, Saudi Arabia. T: +9665 06174015 F: +96665320536robeesanda@yahoo.com

Ann Saudi Med 2007; 27(3): 183-190

The term abdominal compartment syndrome (ACS) describes the clinical manifestations of the pathologic elevation of the intra-abdominal pressure (IAP). When the IAP exceeds $12 \mathrm{~mm} \mathrm{Hg}$ it is referred to as intra-abdominal hypertension (IAH) while ACS generally sets in at an IAP in excess of $20 \mathrm{~mm} \mathrm{Hg}$. This syndrome is most commonly observed in the setting of severe abdominal trauma and in the aftermath of major abdominal operations. ACS affects mainly the respiratory, cardiovascular, renal, gastrointestinal and the central nervous systems. Fundamental to the development of ACS are the obstruction of venous return to the heart via the inferior vena cava and the splinting of the diaphragm due to elevated IAP. Preventing ACS by the identification of patients at risk and early diagnosis is paramount to its successful management. To this end a high index of suspicion is sine qua non. The management of established ACS requires clinical astuteness and decisiveness with a readily available and generous team support. The purpose of this review is to enhance awareness among clinicians about a subtle condition with a devastating impact on morbidity and mortality if undiagnosed.

$\mathrm{T}$ here are three important considerations to be made in attempting to understand the abdominal compartment syndrome (ACS). Firstly, the abdomen is a conduit of major blood vessels of the body as they course to and from the organs that they supply or drain. Secondly, the peritoneal sac, the anterior abdominal wall and the retroperitoneal space are potential restraints that can passively transmit extrinsic pressure on the vessels and restrict circulation. And thirdly, the gut mucosal barrier, contained in the abdominal compartment, is the biological equivalent of a demilitarized zone between two opponents: the pathogenic commensals in the lumen and the reticuloendothelial system.

The abdominal compartment normally sustains a pressure of about $5 \mathrm{~mm} \mathrm{Hg}$, but can be non-pathologically elevated in the obese. ${ }^{1}$ Many pathologic conditions can generate sustained pressures in excess of $12 \mathrm{~mm}$ $\mathrm{Hg}$, a state referred to as intra-abdominal hypertension (IAH), ${ }^{1}$ producing sub-clinical organ dysfunctions (regarded here as prodromes) leading to multiple organ dysfunction syndrome (MODS). Thus, ACS is seen as the end result of a sustained $\mathrm{IAH}_{*}{ }^{1-3}$

\section{Historical Milestones}

Credit for the first recorded account of an abnormal increase in intra-abdominal pressure (IAP) goes to the French physician Etienne-Jules Marey ${ }^{4}$ in 1863. He published a paper titled "Physiologie Medicale de la Circulation $d u$ Sang" and noted that the effects that respiration produces on the thorax are inversely related to those in the abdomen. Wendt, ${ }^{4}$ in 1873 , measured the IAP through the rectum and noted that the higher the IAP the less the secretion of urine. That was the first description of organ dysfunction directly attributable to elevated IAH. In rapid succession others championed our understanding of ACS. Oderbrecht ${ }^{4}$ in 1875 cannulated the urinary bladder and reported that the IAP is normally positive. In 1890 Heinricius $^{4}$ reported that IAP between 27 to $46 \mathrm{cmH}_{2} \mathrm{O}(19.8$ to $33.8 \mathrm{~mm} \mathrm{Hg})$ was uniformly fatal to experimental animals and he attributed his observations to obstruction of ventilation, decreased end-diastolic volume and a low blood pressure.

In the United States, in a luminous paper in 1911, Haven Emerson ${ }^{5}$ reported convincing experimental observations. He noted that the contraction of the diaphragm is the main contributor of IAP during inspiration; that hypnosis and muscle paralysis induced by anesthesia with the concomitant loss of muscle tone results in a decrease in IAP; that elevated IAP leads to an increase in peripheral vascular resistance; and that high IAP results in the death of the animal from cardiac 
failure long before asphyxiation develops.

Sir Heneage Ogilvie ${ }^{6}$ in Britain in 1940 described the use of vaseline impregnated canvas or cotton sutured to the edge of the wound as a way of avoiding closing the abdomen under tension. In a similar endeavor, Gross ${ }^{7}$ in 1948 described the so-called staged abdominal repair (STAR) operative technique in the closure of the abdomen in the management of large omphaloceles. In 1951, Baggot, ${ }^{8}$ an anesthesiologist from Dublin, observed the detrimental effect of IAH on respiratory parameters and noted that forcing distended bowel back into the abdominal cavity of limited volume might kill the patient and he coined the term "acute tension pneumoperitoneum". By 1969 some publications ${ }^{9,10}$ advocated leaving the abdomen open in children with omphalocele and gastroschisis. In 1972 it was observed ${ }^{11}$ that the application of the Military Anti-Shock Trousers (MAST) resulted in decreased cardiac output and depressed renal function.

The most comprehensive description of ACS is credited to Kron et al. ${ }^{12}$ who in 1984 published their observation on IAH and for the first time advocated abdominal re-exploration and decompression as a life-saving intervention, whatever the cause. The first use of the term abdominal compartment syndrome was, however, by Robert Fietsam et al.$^{13}$ Other papers ${ }^{14,15}$ rapidly appeared about this time, confirming earlier observations and defining this syndrome more clearly.

\section{Epidemiology}

The epidemiology of IAH and ACS are intrinsically tied to the level of awareness of these conditions among clinicians and on the population studied; for example, among a trauma population as compared to patients who have undergone damage control surgery. However, studies conducted as recently as in 2006 showed a lack of consensus regarding the definition, functional indications, or management of an open abdomen in the perceptions of Canadian trauma providers despite a high self-reported level of familiarity with ACS. ${ }^{16,17}$ In Australia, ${ }^{18}$ despite familiarity with the technique of intra-abdominal pressure monitoring and the signs of IAH, ICU registrars lacked sufficient understanding of the retroperitoneal causes of, and the threshold for intervention in ACS. And in the United Kingdom, ${ }^{19,20}$ it was observed that fewer patients are diagnosed with ACS in district hospitals than in teaching hospitals and that there was a variable threshold for the diagnosis of the condition as well as disparity in the number of patients who are decompressed suggesting a lack of agreement in the management of this condition.

The point prevalence of IAH and ACS have been estimated at $50.5 \%$ and $8.2 \%$ from a six-country international European collaboration ${ }^{21}$ which showed (in a mixed ICU population) that non-survivors had a significantly higher mean IAP on admission than survivors and that independent predictors of mortality included age, APACHE II score, the type of ICU (odds ratio 2.5 medical vs. surgical) and the presence of liver dysfunction. Studies from Germany ${ }^{22}$ and the $\mathrm{USA}^{23}$ have reported mortality rates of around $60 \%$ from ACS in intensive care units.

The World Society for the Abdominal Compartment Syndrome (WSACS $)^{24}$ is championing research in and promoting the awareness of this disorder. To standardize terms and definitions, it has just launched the most authoritative textbook ${ }^{25}$ on the subject at its recently concluded 3rd congress held in the city of Antwerp, Belgium from March 21-24, 2007.

\section{Etiology and Classification}

The WSACS has classified ACS into three categories: primary, secondary and tertiary (recurrent) types. Primary ACS is defined as "a condition associated with injury or disease in the abdomino-pelvic region that frequently requires early surgical or radiological intervention." ${ }^{1}$ Examples of etiologic factors here include severe blunt and penetrating abdominal trauma, ${ }^{26-28}$ ruptured abdominal aortic aneurysm or a leak from an aneurismal repair, ${ }^{29-31}$ damage control surgery with packing of the liver, ${ }^{32,33}$ primary closure of the abdomen under tension, ${ }^{34}$ and pelvic fractures or extraperitoneal hemorrhage. ${ }^{35-37}$ Patients who undergo an initial trial of non-operative management for solid organ injuries and who subsequently develop ACS are included in the primary category. Secondary ACS is defined as due to "conditions that do not originate from the abdomino-pelvic region". ${ }^{1}$ Examples of causes of secondary ACS include sepsis and capillary leak, ${ }^{38-}$ ${ }^{40}$ severe acute pancreatitis (SAP), ${ }^{41,42}$ major thermal burns ${ }^{43-46}$ and other conditions requiring massive fluid resuscitation. ${ }^{47-49}$ Tertiary (recurrent) ACS "refers to the condition in which ACS redevelops following previous surgical or medical treatment of primary or secondary ACS", 1,50

\section{Pathophysiology}

\section{Gastrointestinal System}

Fundamental to the understanding of the pathophysiology of ACS is the understanding of the concept of abdominal perfusion pressure (APP) in much the same way as cerebral perfusion pressure (CPP) is in relation to raised intracranial pressure. APP is the difference 
between the mean arterial pressure (MAP) and intraabdominal pressure (IAP) which is represented mathematically as:

\section{APP $=$ MAP-IAP}

An APP of $50 \mathrm{~mm} \mathrm{Hg}$ or higher is the optimum resuscitation goal in all critically ill patients. ${ }^{51}$

Splanchnic ischemia (the "first hit") caused by hemorrhage is the initiating event ${ }^{52,53}$ leading to neutrophil priming, which promotes local and remote organ injury by several immune-mediated mechanisms $s^{54,55}$ that include free-radicals like superoxide, enzymes for membrane degradation like elastase, increased CD11b/ CD18 expression for endothelial adhesion, elaboration of the chemo-attractant IL-8 to recruit more neutrophils and delayed apoptosis to sustain cytotoxicity. ${ }^{56}$ Decompressive laparotomy (DL) as the definitive treatment of ACS brings with it fresh problems (the second hit) to this pathophysiological conundrum. ACS relieved by DL allows a bolus of inflammatory agents to enter the systemic circulation and constitutes an ischaemia-reperfusion injury. ${ }^{57}$ Mesenteric lymphatic circulation has been implicated as the conduit for the systemic distribution of proinflammatory cytokines, metabolites of arachidonic acid, ${ }^{58}$ complement $^{59}$ and bacterial translocation. ${ }^{60}$ This has been proposed as the mechanism for remote organ injury, capillary leak and endotoxemia in ACS (Figure 1). ${ }^{61-63}$

\section{Cardiovascular System}

IAH affects the cardiovascular system by disturbing preload, myocardial contractility and afterload. ${ }^{64}$ Low preload may be due to absolute loss of intravascular volume or relative loss through the compression of the inferior vena cava (IVC) as it traverses the diaphragmatic hiatus. Pooling of blood in the pelvis and the lower extremities constitutes a loss and may be a factor in the pathogenesis of deep venous thrombosis. ${ }^{65}$

The increased intra-thoracic pressure increases pulmonary vascular resistance and decreases right ventricular preload compromising the ability of the thin-walled right ventricle (RV) to effect adequate right ventricular ejection fraction (RVEF) and a consequent decrease in left ventricular end-diastolic volume and diminished left ventricular ejection fraction (LVEF). The resultant low cardiac output (CO) triggers a compensatory tachycardia and a consequent shortened cardiac cycle (at the expense of diastolic time) leading to impaired coronary blood flow. Thus, at the time the heart has to work the hardest, its own blood supply is impaired (Figure 1). The compensatory peripheral vascular resistance due to

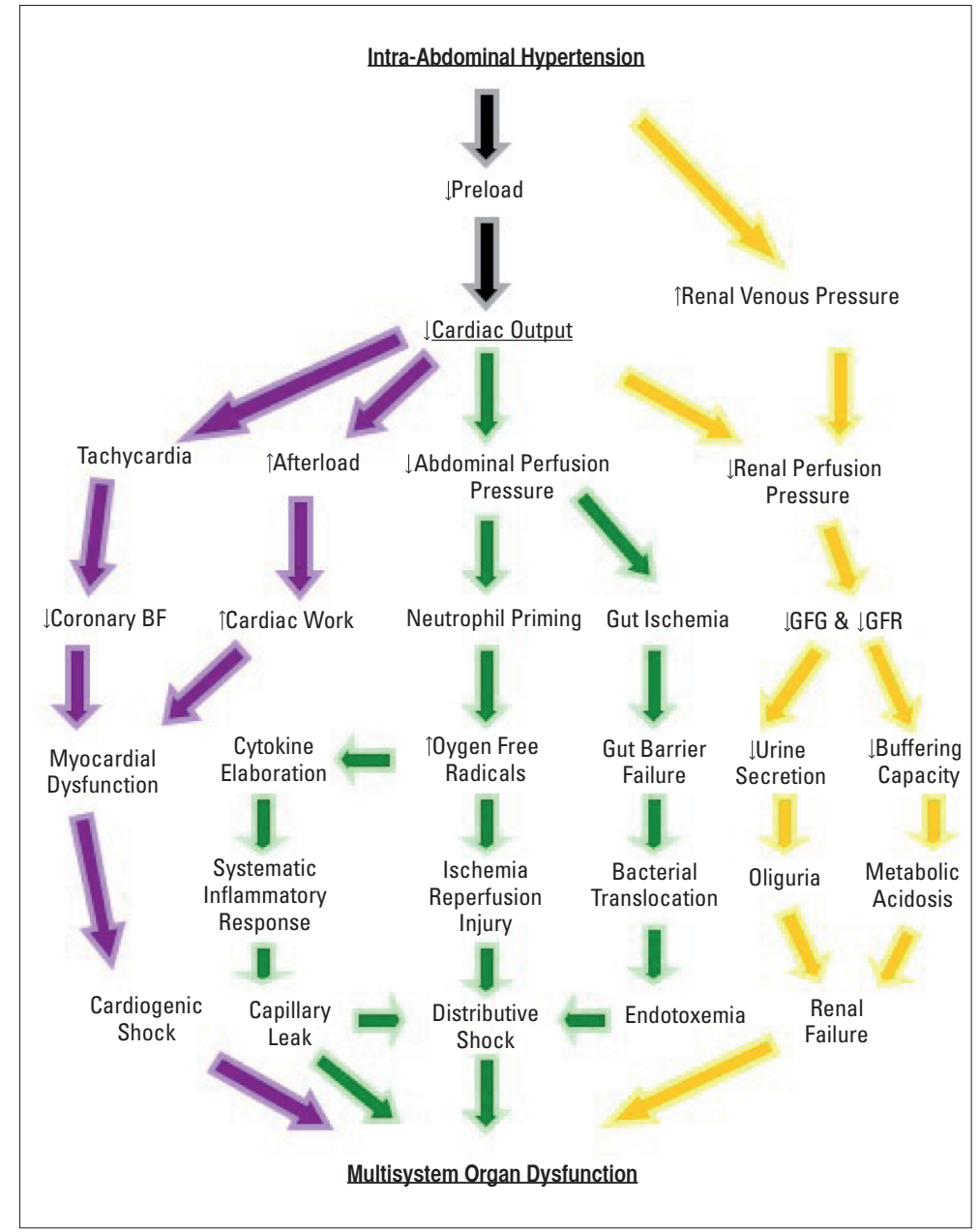

Figure 1. Pathophysiology of intra-abdominal hypertension on the cardiovascular (purple arrows), gastrointestinal (green arrows) and the renal (orange arrows) systems producing multisystem organ dysfunction in abdominal compartment syndrome. SIRS = systemic inflammatory response syndrome, GFG = glomerular filtration gradient, GFR = glomerular filtration rate, $\mathrm{BF}=$ blood flow .

the low cardiac output together with the compressive effect of IAH on the aorta and its branches contribute towards the low APP.

\section{Respiratory System}

Raised IAP is transmitted across the diaphragm producing elevated intra-thoracic pressure, compressive atelectasis, increased alveolar dead space, reduced functional residual capacity, ventilation-perfusion mismatch and hypoxic bronchial artery vasoconstriction. By the same token, the splinting of the diaphragm leads to the need to use the accessory muscles of respiration in the presence of diminished chest wall compliance and so increases the work of breathing. In patients under mechanical ventilation, the decreased dynamic lung and 


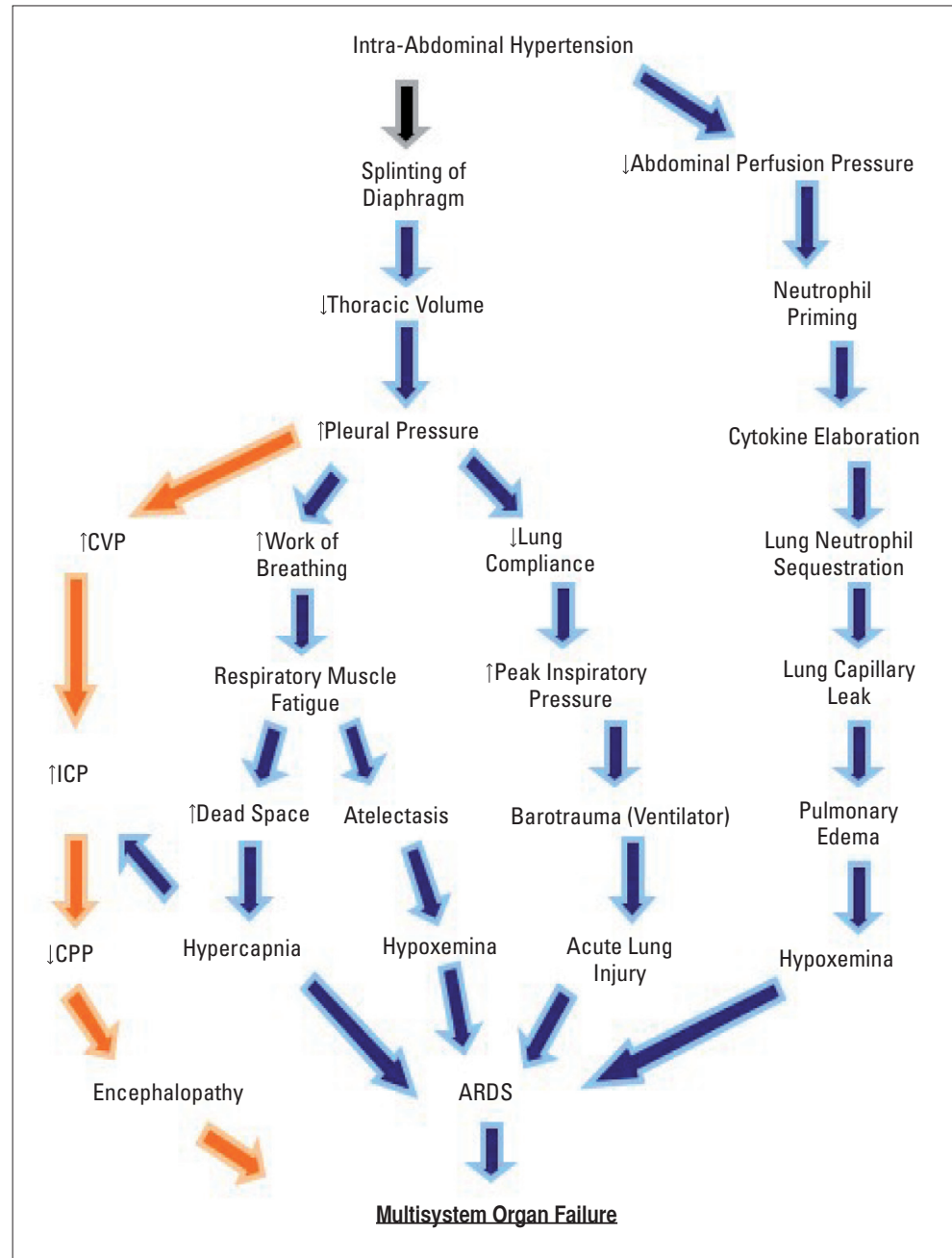

Figure 2. . Pathophysiology of intra-abdominal hypertension on the respiratory (blue arrows) and the central nervous (orange arrows) systems producing multisystem organ dysfunction in abdominal compartment syndrome. CVP = central venous pressure, ICP $=$ intra-cranial pressure, $\mathrm{CPP}=$ cerebral perfusion pressure, $\mathrm{ARDS}=$ adult respiratory distress syndrome.
Joseph et $\mathrm{al}^{68}$ studied the effects of raising the IAP using pneumoperitoneum on ICP and CPP. They demonstrated that IAH increases ICP and concluded that laparoscopy would be harmful in patients with head injury. Subsequently, reports of the detrimental effects of pneumoperitoneum on $\mathrm{ICP}^{69}$ and the beneficial effects of DL on $\mathrm{ICP}^{70}$ appeared confirming the earlier assertions. It has, therefore, been proposed that the monitoring of IAP in patients with head trauma and abdominal trauma be routine. ${ }^{71,72}$

\section{Renal System}

The effect of IAH on the renal system is multi-factorial and includes decreases in $\mathrm{CO}$, renal perfusion pressure (RPP), glomerular filtration gradient (GFG), microcirculatory flow, direct compression of the renal cortex, and increased renal venous pressure (RVP) ${ }^{73}$ Of these, it appears that increased RVP plays the most significant role in the pathogenesis of IAH-induced renal failure (Figure 1) ${ }^{74}$ The reduction of RPP and the reduction in the GFG (the net force acting across the glomerulus) as well as the effects of the hormones vasopressin, reninangiotensin and aldosterone probably work in concert to produce renal failure in IAH.

\section{The Abdominal Wall}

IAH reduces the abdominal wall blood flow by the direct compressive effect. Blood flow to the rectus abdominis muscle is reduced by $60 \%$ at an IAP above 10 $\mathrm{mm} \mathrm{Hg}$. As collagen deposit and resistance to infection are directly proportional to tissue perfusion and oxygenation, elevated IAP adversely affects wound healing and leads to wound dehiscence. ${ }^{75}$

\section{Diagnosis}

ACS has been described as the presence of a tensely distended abdomen, elevated intra-abdominal and peaked airway pressure, inadequate ventilation with hypoxia and hypercarbia, impaired renal function, and a documented improvement of these features after DL. ${ }^{76}$ While the virtues of clinical assessment cannot be debated, the detection of IAH by palpation of the abdomen has proved to be insensitive in differentiating IAPs of 10 from $20 \mathrm{~mm} \mathrm{Hg}^{77}$ and serial measurement of the abdominal circumference did not show any correlation with the IAP. ${ }^{78}$ Therefore, the identification of patients at risk of developing IAH carries with it the responsibility for a deliberate and diligent monitoring of IAP, especially in patients that are comatosed or intubated.

The abdominal CT scan has a role in identifying ACS in selected patients by the following subtle findings: 
+ Round-belly sign-Abdominal distention with an increased ratio of anteroposterior-to-transverse abdominal diameter (ratio $>0.80 ; P<0.001$ );

+ Collapse of the vena cava;

+ Bowel wall thickening with enhancement;

+ Bilateral inguinal herniation. ${ }^{79}$

In the 144 years since the publication of the findings of Etienne-Jules Marey, ${ }^{4}$ the techniques of IAP have gone through several modifications. A detailed description of each technique is beyond the scope of this article but those interested can find them in the WSACS textbook. ${ }^{80}$ The first method described to find clinical applicability was by Kron et al. ${ }^{12,81}$ This method entails instillation of $60 \mathrm{~mL}$ of saline through the bladder using an indwelling Foley's catheter. The outlet is then clamped and through a wide-bore needle connected to a manometer or pressure transducer and the pressure is measured. This method has several drawbacks, which include the disruption of the otherwise closed drainage system of the bladder, thereby not safeguarding sterility. The other drawbacks are that the use of needles predisposed healthcare workers to needle-stick injuries and was time-consuming.

Iberti et $\mathrm{al}^{15,82}$ introduced a modification that had some of the short-comings of the previous method with the advantage that it is simpler, less time-consuming and needed less manipulation. About a decade later, Cheatham and Safcsak ${ }^{83}$ introduced a modification that was revised by Malbrain ${ }^{84}$ which serves as the current standard for the intra-vesical technique. Using a threeway Foley's catheter, investigators in Australia ${ }^{85}$ have shown that a continuous measurement of IAP is possible and of practical advantage in critically ill patients.

Aside from the intra-vesical route, the same principle has been applied in measuring the IAP from catheters inserted into the stomach. A novel method using a fully automated system, the Air-Pouch System (or Spiegelberg System), measures IAP and gastric $\mathrm{pH}$ via a nasogastric tube. ${ }^{86}$ This system has been tested in an experimental setup with an excellent correlation $\left(r^{2}=0.99\right)$ with direct insufflator pressure ${ }^{87}$ Clinical validation in ICU patients and during laparoscopic surgery has shown excellent correlation $\left(r^{2}=0.96\right)$ with the standard intravesical method. ${ }^{88}$ There are on-going efforts to improve on the accuracy and reliability of the current techniques of IAP measurement using piezo-resistive techniques that are showing promising results. ${ }^{89}$

Other routes have been described for the measurement of IAP using the foregoing principle, but none of these have found widespread clinical use. These are the rectum, ${ }^{90}$ the uterus ${ }^{91}$ and the inferior vena cava (IVC) ${ }^{92}$
The problem with the rectal route is that residual faecal matter may block the catheter tip and give an erroneous reading and nursing staff have an aversion for this route. The uterine method has a distinct disadvantage in that it can only be used in females and may be resisted by virgins. The other disadvantage is that it carries the risk of introducing infection and cannot be used in patients with uterine bleeding. The IVC route employs the placement of a central venous catheter through either the SVC or through the femoral veins and is guided into place within the abdominal compartment. The disadvantage of the IVC route is the risk of catheter-related infections and the technical difficulty in the initial insertion.

\section{Management}

A subset of ACS can be prevented and to this end, there is no substitute for clinical astuteness, sound judgment and good operative technique. Early goal-directed therapy using the APP in critically-ill or traumatized patients during the resuscitation phase may avert the dangers of over-enthusiastic fluid resuscitation. Confining DCS to the shortest time possible to give opportunity to correct acidosis, hypothermia and coagulopathy - the so-called deadly triad of ACS - is appropriate. Gentle handling of tissue intra-operatively and the avoidance of primary closure of the abdomen under tension are the defining qualities and the hallmarks of good surgical handicraft. It is generally advocated that when the abdominal contents can be viewed protruding above the wound margin when looking across the table at the level of the anterior abdominal wall, temporary abdominal closure (TAC) is the option of choice. ${ }^{93,94}$

Burch et $\mathrm{al}^{95}$ proposed a four-category grading system for IAH as follows:
Grade I
$10-15 \mathrm{~cm} \mathrm{H}_{2} \mathrm{O}(7.5-11 \mathrm{~mm} \mathrm{Hg})$;
Grade II
$15-25 \mathrm{~cm} \mathrm{H}_{2} \mathrm{O}(11-18 \mathrm{~mm} \mathrm{Hg})$;
Grade III $25-35 \mathrm{~cm} \mathrm{H}_{2} \mathrm{O}(18-25 \mathrm{~mm} \mathrm{Hg})$; and
Grade IV $>35 \mathrm{~cm} \mathrm{H}_{2} \mathrm{O}$ (>25 mm Hg).

The authors advocated conservative management for grades I and II and DL for grades III and IV. At first glance, this is useful and practical but, in reality, many surgeons are skeptical about the whole concept of IAH and ACS and would not readily take a patient with, say severe pancreatitis with an IAP of $25 \mathrm{~mm} \mathrm{Hg}$, from the ICU to the OR for a DL. This is where the problem lies: the decision to subject a critically ill medical patient with hemodynamic instability (somebody else's headache!) to the additional hazards of the trauma of surgery and general anaesthesia. On the contrary, many published papers show ample evidence that such intervention re- 
sults in substantial benefit to the patient with improved survival and diminished morbidity. ${ }^{41,96-100}$

There are critically ill patients with IAH and ACS in whom a trial of conservative (medical) management would be appropriate. This may wholly, or in part, be due to four reasons: DL is associated with a less than perfect survival outcome (38-71\%); ${ }^{101}$ the complications and the cost of management of patients with TAC may be prohibitively high; there are subsets of patients in whom DL may not be necessary; and consent for operation may have been withheld. ${ }^{102}$

The evidence for conservative management is limited by the lack of randomized studies. Therefore, a lot of what is published is based on limited experience and anecdotal reports. Massive distension of the abdomen by postoperative ileus or intra-abdominal pathology may contribute significantly to IAH for which correction of underlying etiologic factors like electrolyte imbalance or the use of prokinetic drugs like erythromycin, metoclopramide, neostigmine, insertion of nasogastric and rectal tubes or colonoscopic decompression may be accompanied by a reduction of IAP. Faecal impaction and intractable constipation may respond to suppositories, enemas or manual disimpaction. In patients under mechanical ventilation, the use of neuromuscular blockade may be a temporizing measure by paralyzing the muscles of the abdominal wall and considerably lowering the IAP. Diuretics and dialysis might help in removing excess interstitial fluid that has contributed to visceral edema in cases where massive fluid requirement for resuscitation led to IAH and ACS such as in burns and SAP. Tapping of a massive ascites may be rewarded with an immediate reduction in IAP, but it is also in these patients with liver failure that the coagulopathy may contraindicate DL. ${ }^{102}$

Where operative intervention is indicated in the treatment of ACS, the operative technique involves opening the abdomen, managing the open abdomen and closing it. The abdomen may be opened for damage-control surgery where the operation is abbreviated and focuses on life-threatening problems like bleeding or it may be planned to release tension in the abdomen such as will be caused by SAP. Prior to this procedure, however, serious complications of reperfusion injury must be anticipated and planned for. A decompression cocktail' made of one liter of normal saline, sodium bicarbonate and $50 \mathrm{~g}$ of mannitol is administered. This is aimed to increase the circulatory volume, to neutralize a large amount of acidic metabolites from the mesenteric vascular bed and to enhance diuresis to prevent acute tubular necrosis. This is then followed by a temporary abdominal closure which is aimed at ensuring the IAP is not raised by a primary fascial closure (PFC) and to permit easy access to the contents of the abdomen after resuscitation of the patient. ${ }^{103}$ Managing the open $a b$ domen is froth with many problems that include sepsis and negative nitrogen balance from loss of fluid from the wound.

Four methods TAC have been described: towel clip closure, Bogota bag closure, mesh closure, and vacuumassisted wound closure. ${ }^{104}$ The towel clip closure method is the cheapest and easiest method and entails using a series of towel clips to hold the edge of the skin at distances 2 to $3 \mathrm{~cm}$ apart after hemorrhage has been controlled. The Bogota bag uses a split infusion bag sutured to the edge of the wound to cover the viscera. Mesh closure employs absorbable meshes on the fascial edges with the omentum, if present, interposed between the mesh and the bowels to minimize the risk of fistula formation. The vacuum-assisted technique involves placing a fenestrated non-adherent plastic sheet inside the abdomen extending bilaterally under the anterior abdominal wall followed by a layer of polyurethane sponge that is cut to size and sutured to the edge of the wound incorporating fenestrated tubes connected to vacuum. These are covered with a final air-tight adhesive film. ${ }^{105,106}$

Closure of the open abdomen is planned when edema has subsided and PFC is feasible. Gradual wound closure is attempted using interrupted transverse sutures on the superior and inferior edges of the incision. ${ }^{104}$ The technique of component separation ${ }^{107}$ is helpful to achieve PFC and involves the partial separation of the muscles of the anterior abdominal wall at the level of their aponeuroses on the abdominal recti in a vertical direction while preserving the neurovascular bundles. A new technique was reported from Sweden using vacuum-assisted closure and gradual shortening of non-absorbable meshes sutured to the wound edges with good results. ${ }^{107}$ The use of tissue expanders to aid in PFC is known as well as the use of pedicle or free latissimus dorsi flaps to reconstruct the abdominal wall. ${ }^{108}$

Finally, we must not forget the courageous, lone surgeon working in austere parts of the world without devices for vacuum-assisted wound closure or who may not be familiar with using them. The use of a skin only closure may be a safe and wise option in the aftermath of DCS under such circumstances. The incisional hernia thus created can be repaired at a later date and would amount to an acceptable trade-off for the patient to end up with a temporary disability (hernia) than to risk death by ACS. 


\section{REFERENCES}

1. Malbrain MLNG, De Laet I, Cheatham M. Consensus Conference Definitions and Recommendations on intra-abdominal hypertension (IAH) and the Abdominal Compartment Syndrome (ACS) - the long road to the final publications, how did we get there? Acta Clinica Belgica. 2007; 62: (supplement 1). P. 44-59.

2. Hunter JD, Damani Z. Intra-abdominal hypertension and the abdominal compartment syndrome. Anaesthesia. 2004 Sep; 59(9):899-907.

3. Moore AF, Hargest $R$, Martin M, Delicata RJ. Intra-abdominal hypertension and the abdominal compartment syndrome. Br J Surg. 2004 Sep; 91(9):1102-10.

4. Schein M. Abdominal Compartment Syndrome: Historical Background. In: Ivatury RR, Cheatham ML, Malbrain MLNG, Sugrue M (Editors). Abdominal Compartment Syndrome. Landes Bioscience. 2006. P. 1-7.

5. Emerson H. Intra-Abdominal pressures. Arch Intern Med 1911: 7:754-784.

6. Ogilvie WH. The late complications of abdomina war wounds. Lancet 1940; 2:253-256.

7. Gross RE. A new method for surgical treatment of large omphaloceles. Surgery 1948; 24:277-292.

8. Baggot MG. Abdominal blow-out: a concept Current Research Anesthesia Analgesia. 1951 30:295-8.

9. Ravitch MM. Omphalocle: secondary repair with the aid of pneumoperitoneum. Arch Surg. 1969; 99:166-170.

10. Allen RG, Wrenn EL, Jr. Silo as a sac in the treatment of omphalocele and gastroschisis. J Ped Surg. 1969; 4:3-8.

11. Shenansky JH, Gillenwater JY. The renal hemodynamic and functional effects of external counterpressure. Surg Gynecol Obstet. 1972; 134:253-258.

12. Kron IL, Harman PK, Nolan SP. The measure ment of intra-abdominal pressures a criterion for abdominal re-exploration. Ann Surg. 1984; 199:28 30.

13. Fietsam R Jr, Villalba M, Glover JL, Clark K. Intra-abdominal compartment syndrome as a complication of ruptured abdominal aortic aneurysm repair. Am Surg. 1989; 55:396-402.

14. Cullen DJ, Coyle JP, Teplick R, Long MC. Cardiovascular, pulmonary, and renal effects of massively increased intra-abdominal pressure in critically ill patients. Crit Care Med. 1989: 17:118-21.

15. Iberti TJ, Lieber CE, Benjamin E. Determination of intra-abdominal pressure using a transurethra bladder catheter: clinical validation of the technique. Anesthesiology. 1989; 70:47-50.

16. Karmali S, Evans D, Laupland KB, Findlay C, Bal $\mathrm{CG}$, Bergeron $\mathrm{E}$, et al. To close or not to close, that is one of the questions? Perceptions of Trauma Association of Canada surgical members on the management of the open abdomen. J Trauma. 2006 Feb; 60(2):287-93.

17. Kirkpatrick AW, Laupland KB, Karmali $S$ Bergeron E, Stewart TC, Findlay C, et al. Spill you guts! Perceptions of Trauma Association of Canada member surgeons regarding the open abdomen and the abdominal compartment syndrome. $J$ Trauma. 2006 Feb; 60(2):279-86.

18. Nagappan R, Ernest D, Whitfield A. Recognition and management of intra-abdominal hypertension and abdominal compartment syndrome. Crit Care Resusc. 2005 Dec; 7(4):298-302.

19. Tiwari $A$, Myint $F$, Hamilton $G$. Recognition and management of abdominal compartment syndrome in the United Kingdom. Intensive Care Med. 2006 Jun; 32(6):906-9.

20. Ravishankar N, Hunter J. Measurement of in tra-abdominal pressure in intensive care units in the United Kingdom: a national postal questionnaire study. Br J Anaesth. 2005 Jun; 94(6):763-6. 21. Malbrain MLNG, Chiumello D, Pelosi P, Wilmer A, Brienza N, Malcangi V, et al. Prevalence of intraabdominal hypertension in critically ill patients: a multicentre epidemiological study. Intensive Care Med. 2004 May; 30(5):822-9.

22. Schachtrupp A, Jansen M, Bertram P, Kuhlen $\mathrm{R}$, Schumpelick V. Abdominal compartment syndrome : Significance, diagnosis and treatment Anaesthetist. 2006 Jun; 55(6):660-667.

23. Mcnelis J, Soffer S, Marini CP, Jurkiewicz A Ritter G, Simms HH, et al. Abdominal compartment syndrome in the surgical intensive care unit. Am Surg. 2002 Jan; 68(1):18-23.

24. http://www.wsacs.org

25. Ivatury RR, Cheatham ML, Malbrain MLNG, Sugrue M (Editors). Abdominal Compartment Syndrome. Landes Bioscience. 2006

26. Pleva L, Sir M, Mayzlik J. Abdominal compartment syndrome in polytrauma. Biomed Pap Med Fac Univ Palacky Olomouc Czech Repub. 2004 Jul; 148(1):81-4.

27. Flores-Alvarez $\mathrm{E}$, Avila-Cuevas GE, de la TorresGonzalez JC, Rivera-Barragan V, Lopez-Rodriguez $\mathrm{JL}$, Reynoso-Talamantes D. Early diagnosis and risk factors associated with abdominal compartment syndrome. Cir Cir. 2005 May-Jun; 73(3):179-83.

28. Chen RJ, Fang JF, Chen MF. Intra-abdomina pressure monitoring as a guideline in the nonoperative management of blunt hepatic trauma. $J$ Trauma. 2001 Jul: 51(1):44-50.

29. Rasmussen TE, Hallett JW Jr, Noel AA, Jenkins G, Bower TC, Cherry KJ Jr, et al. Early abdomina closure with mesh reduces multiple organ failure after ruptured abdominal aortic aneurysm repair guidelines from a 10 -year case-control study. $J$ Vasc Surg. 2002 Feb; 35(2):246-53.

30. Mehta M, Darling RC III, Roddy SP, Fecteau S, Ozsvath KJ, Kreienberg PB, et al. Factors associated with abdominal compartment syndrome complicating endovascular repair of ruptured $a b-$ dominal aortic aneurysms. J Vasc Surg. 2005 Dec; 42(6):1047-51

31. Djavani K, Wanheinen A, Bjorck M. Intra-abdominal hypertension and abdominal compartment syndrome following surgery for ruptured abdominal aortic aneurysm. Eur J Vasc Endovasc Surg 2006 Jun; 31(6):581-4.

32. Brasel KJ, Weigelt JA. Damage control in trauma surgery. Curr Opin Crit Care. 2000 Aug 6(4):276-280

33. Stagnitti F, Mongardini M, Schillaci F, Ribaldi S, Priore F, Corona F, et al. Packing: current concepts of "life-saving" surgery. G Chir. 2003 Aug-Sep; 24(89):315-22.

34. Hut'an M, Salapa M, Vandriakova R, Poticny V Rupture of the laparotomy incision and its suture using Ventrofilm. Rozhl Chir. 2001 Mar; 80(3):124-7. 35. O'Mara MS, Semins H, Hathaway D, Caushaj PF. Abdominal compartment syndrome as a consequence of rectus sheath hematoma. Am Surg. 2003 Nov; 69(11):975-7.

36. Davutoglu V, Kervancioglu S, Sezen Y. Large rectus muscle hematoma with intraperitoneal bleeding and fatal abdominal compartment syndrome complicating anticoagulant therapy. Clin Appl Thromb Hemost. 2005 Jan; 11(1):109-11.

37. Ernits M, Mohan PS, Fares LG 2nd, Hardy H 3rd. A retroperitoneal bleed induced by enoxaparin therapy. Am Surg. 2005 May; 71(5):430-3.

38. Holzheimer RG, Gathof B. Re-operation for complicated secondary peritonitis - how to identify patients at risk for persistent sepsis. Eur J Med Res. 2003 Mar 27; 8(3):125-34.
39. Sullivan KM, Battey PM, Miller JS, McKinnon WM, Skardasis GM. Abdominal compartment syndrome after mesenteric revascularization. J Vasc Surg. 2001 Sep; 34(3):559-61.

40. Stagnitti F, Calderale SM, Priore F, Ribaldi S, Tiberi $\mathrm{R}$, Pascalis $\mathrm{M}$, et al. Abdominal compartment syndrome: pathophysiologic and clinic remarks. G Chir. 2004 0ct; 25(10):335-42.

41. Tao J, Wang C, Chen L, Yang Z, Xu Y, Xiong J, et al. Diagnosis and management of severe acute pancreatitis complicated with abdominal compartment syndrome. J Huazhong Univ Sci Technolog Med Sci. 2003; 23(4):399-402.

42. Alberti A, Giannetto G, Littori F, DiMarco D, Dattola P, Dattola A, et al. Abdominal compartment syndrome in video laparoscopic surgery. Etiopathogenetic aspects, physiopathology and personal experience. Chir Ital. 1998 Mar-Aug; 50(24):35-42.

43. Oda J, Yamashita K, Inoue T, Harunari N, Ode $Y$, Mega $K$, et al. Resuscitation fluid volume and abdominal compartment syndrome in patients with major burns. Burns. $2006 \mathrm{Mar}$; 32(2):151-4.

44. O'Mara MS, Slater H, Goldfarb IW, Caushaj PF. A prospective, randomized evaluation of intraabdominal pressures with crystalloid and colloid resuscitation in burn patients. J Trauma. 2005 May; 58(5):1011-8.

45. Oda J, Ueyama M, Yamashita K, Inoue T, Noborio $M, O d e ~ Y$, et al. Hypertonic lactated saline resuscitation reduces the risk of abdominal compartment syndrome in severely burned patients. $J$ Trauma. 2006 Jan; 60(1):64-71.

46. Jensen AR, Hughes WB, Grewal H. Secondary abdominal compartment syndrome in children with burns and trauma: a potentially lethal complication. J Burn Care Res. 2006 Mar-Apr; 27(2):242-6.

47. Rodas EB, Malhotra AK, Chhitwal R, Aboutanos MB, Duane TM, Ivatury RR. Hyperacute abdominal compartment syndrome: an unrecognized complication of massive intraoperative resuscitation for extra-abdominal injuries. Am Surg. 2005 Nov; 71(11):977-81.

48. Mayberry JC, Welker KJ, Goldman RK, Mullins RJ. Mechanism of acute ascites formation after trauma resuscitation. Arch Surg. 2003 Jul; 138(7):773-6

49. Balogh Z, McKinley BA, Cocanour CS, Kozar RA Valdivia A Sailors RM, et al. Supranormal trauma resuscitation causes more cases of abdominal compartment syndrome. Arch Surg. 2003 Jun; 138(6):637-42.

50. Desender L, De Laet I, Vermassen F, De Waele J. Tertiary Petitonitis and Tertiary ACS: a perfect match? Acta Clinica Belgica. 2007; 62:(suppl 1)304. 51. Cheatham ML, Malbrain MLNG. Abdominal Perfusion Pressure. In: Ivatury RR, Cheatham ML, Malbrain MLNG, Sugrue M (Editors). Abdominal Compartment Syndrome. Landes Bioscience. 2006 .P. $69-81$

52. Pastores SM, Katz DP, Kvetan V. Splanchnic ischemia and gut mucosal injury in sepsis and the multiple organ dysfunction syndrome. Am J Gastroenterol. 1996 Sep; 91(9):1697-710.

53. Diebel LN, Dulchavsky SA, Brown WJ. Splanchnic ischemia and bacterial translocation in the abdominal compartment syndrome. J Trauma. 1997 Nov; 43(5):852-5.

54. Botha AJ, Moore FA, Moore EE, et al. Postinjury neutrophil priming and activation: an early vulnerable window. Surgery. 1995; 118:358-64, discussion 364-5.

55. BiffI WL, Moore EE Zallen G, et al. Neutrophils are primed for cytotoxicity and resist apoptosis in injured patients at risk for multiple organ failure. 
Surgery. 1999; 126:46:42-8.

56. Zallen G, Moore EE, Johnson JL, et al. Circulating postinjury neutrophils are primed for the release of proinflammatory cytokines. J Trauma 1999; 46:42-8.

57. Bathe OF, Chow AW, Phang PT. Splanchnic origin of cytokines in a porcine model of mesenteric ischemia-reperfusion injury. Surgery. 1998; 123:7988.

58. Moore EE. Mesenteric lymph: the critical bridge between dysfunctional gut and multiple organ failure. Shock. 1998; 10:415-6.

59. Riedemann NC, Ward PA Complement in Ischemia Reperfusion Injury. Am J Pathol. 2003; 162:363-7.

60. Hassoun HT, Kone BC, Mercer DW, Moody FG, Weisbrodt NW, Moore FA. Post-injury multiple organ failure: the role of the gut. Shock. 2001 Jan; 15(1):1-10.

61. Zallen G, Moore EE, Johnson JL, et al. Posthemorrhagic mesenteric lymph primes circulating neutrophils and provokes lung injury. J Surg Res. 1999; 83:83-8.

62. Gonzalez RJ, Moore EE, Ciesla DJ, et al. Post hemorrhagic shock mesenteric lymph activates human pulmonary microvascular endothelium for in vitro neutrophil-mediated lung injury: the role of intercellular adhesion molecule-1. J Trauma. 2003 54:219-23.

63. Deitch EA Adams $\mathrm{C}, \mathrm{L} u \mathrm{O}$ et al A time course study for the protective effect of mesenteric lymph duct ligation on hemorrhagic shock-induced pulmonary injury and the toxic effects of lymph from shocked rats on endothelial cell monolayer permeability. Surgery. 2001; 129:39-47.

64. Cheatham ML, Malbrain MLNG. Intraabdomina Hypertension and the Cardiovascular System. In: Ivatury RR, Cheatham ML, Malbrain MLNG, Sugrue M (Editors). Abdominal Compartment Syndrome. Landes Bioscience. 2006. P. 89-104.

65. Barnes GE, Laine GA, Giam JY. Cardiovascula responses to elevation of intra-abdominal pressure. Am J Physiol. 1985; 248:R208.

66. Cullen DJ, Coyle JP, Teplick R, et al. Cardiovascular, pulmonary, and renal effects of massively increased intraabdominal pressure in critically ill patients. Crit Care Med. 1989; 17(2):118-21.

67. Saggi B, Sugerman HJ, Ivatury RR, et al. Abdominal compartment syndrome. J Trauma. 1998 45(3):597-609.

68. Joseph LG, Este-McDonald JR, Birkett DH, et al. Diagnostic laparoscopy increases intracrania pressure. J Trauma. 1994; 36(6):815-8.

69. Irgau I, Koyfman Y, Tikellis JI. Elective intraoperative intracranial pressure monitoring during laparoscopic cholecystectomy. Arch Surg. 1995 130(9):1011-3.

70. Bloomfield GL, Dalton JM, Sugerman HJ, et al. Treatment of increasing intracranial pressure secondary to the acute abdominal compartment syndrome in a patient with combined abdomina and head trauma. J Trauma. 1995; 39(6):1168-70.

71. Citerio G, Berra L. Intra-abdominal hypertension and the central nervous system. In: Ivatury RR, Cheatham ML, Malbrain MLNG, Sugrue M (Editors). Abdominal Compartment Syndrome. Landes Bioscience. 2006. P.144-56.

72. De Laet I, Citerio G, Malbrain MLNG. The influence of intra-abdominal hypertension on the central nervous system: current insights and clinical recommendations, is it all in the head? Acta
Clinica Belgica. 2007; 62(suppl 1):89-97

73. De Laet I, Malbrain MLNG, Jadoul JL, Rogiers P, Sugrue M. Renal implications of increased intraabdominal pressure: are the kidneys the canary for abdominal hypertension? Acta Clinica Belgica. 2007; 62(suppl.1):119-30.

74. Doty JM, Saggi BH, Sugerman HJ, Blocher CR Pin R, Fakhry I, et al. Effect of increased renal venous pressure on renal function. J Trauma. 1999 47:1000-3.

75. Nathens $A B$, Brenneman FD, Boulanger $B R$ The abdominal compartment syndrome. Can J Surg. 1997; 4:254

76. Ivatury RR, Diebel LN, Potter JM, et al. Intraabdominal hypertension and the abdominal compartment syndrome. Surg Clin North Am 1997; 77(4):783-800.

77. Kirkpatrick AW, Brenneman FD, MacLean RF et al. Is clinical examination an accurate indicato of raised intra-abdominal pressure in critically injured patients? Can J Surg. 2000; 43(3):207-11.

78. Van Mieghem N, Verbrugghe W, Daelemans

$\mathrm{R}$, et al. Can abdominal perimeter be used as an accurate estimation of intra-abdominal pressure? Crit Care.2003; 7[Suppl 2]:P183

79. Pickhardt PJ, Shimony JS, Heiken JP, Buchman TG, Fisher AJ. The abdominal compartment syndrome: CT findings. AJR. 1999 Sep; 173(3): 575-9. 80. Malbrain MLNG, Jones F. Intra-abdominal Pressure Measurement Techniques. In: Ivatury RR, Cheatham ML, Malbrain MLNG, Sugrue M (Editors). Abdominal Compartment Syndrome. Landes Bioscience. 2006. P. 19-68.

81. Kron IL. A simple technique to accurately determine intra-abdominal pressure. Crit Care Med 1989; 17(7):714-5.

82. Iberti TJ, Kelly KM, Gentili DR, et al. A simple technique to accurately determine intra-abdominal pressure. Crit Care Med. 1987; 15(12):1140-2.

83. Cheatham ML Safcsak K Intra-abdominal pressure: a revised method for measurement. $J$ Am Coll Surg. 1998; 186(5):594-5

84. Malbrain MLNG. Different techniques to measure intra-abdominal pressure (IAP): time for critical re-appraisal. Intensive Care Med. 2004 Aug; 30(8):1692.

85. Balogh Z, Jones F, D'Amours S, Parr M, Sugrue $M$. Continuous intra-abdominal pressure measurement technique. Am J Surg. $2004 \mathrm{Dec}$ 188(6):679-84

86. www spiegelberg de

87. Schachtrupp A, Tons C, Fackeldey V, et al. Evaluation of two novel methods for the direct and continuous measurement of the intra-abdomina pressure in a porcine model. Intensive Care Med. 2003; 29(9):1605-8.

88. Malbrain MLNG. Validation of a novel fully automated continuous method to measure intraabdominal pressure. Intensive Care Med. 2003, 29[suppl. 1]:S73

89. Schachtrupp A, Henzler D, Orfao S, Schaefe W, Schwab R, Becker $P$, et al. Evaluation of a modified piezoresistive technique and a watercapsule technique for direct and continuous measurement of intra-abdominal pressure in a porcine model. Crit Care Med. 2006 Mar; 34(3):745-50. 90. Shafik A, El-Sharkawy A, Sharaf WM. Direct measurement of intra-abdominal pressure in various conditions. Eur J Surg. 1997; 163(12):883-7.

91. Dowdle M. Evaluating a new intra-uterine pressure catheter. J Reprod Med. 1997: 42.506-13.
92. Lee SL, Anderson JT, Kraut EJ, et al. A simplified approach to the diagnosis of elevated intraabdominal pressure. J Trauma. 2002; 52(6):1169-

93. Offner PJ, de Souza AL, Moore EE, Biffl WL, Franciose RJ Johnson $\mathrm{JL}$ et al. Avoidance of abdominal compartment syndrome in damagecontrol laparotomy after trauma. Arch Surg. 2001 Jun; 136(6):676-81.

94. Miller RS, Morris JA Jr., Diaz JJ Jr, Herring MB, May AK. Complications after 344 damagecontrol open celiotomies. J Trauma. $2005 \mathrm{Dec}$; 59(6):1365-71; discussion 1371-4.

95. Burch JM, Moore EE, Moore FA, Franciose R. The abdominal compartment syndrome. Surg Clin North Am. 1996;76(4):883-42.

96. Tao HO, Zhang JX, Zou SC. Clinical characteristics and management of patients with early acute severe pancreatitis: experience from a medical center in China. World J Gastroenterol. 2004; 10:919-21.

97. Pupelis G, Austrums E, Snippe K, Berzins M. Clinical significance of increased intra-abdominal pressure in severe acute pancreatitis. Acta Chir Belg. 2002; 102:71-4.

98. Gecelter G, Fahoum B, Gardezi S, Schein M. Abdominal compartment syndrome in severe acute pancreatitis: an indication for a decompressive laparotomy? Dig Surg. 2002; 19:402-4; discussion 404-5.

99. Leppaniemi A, Kemppainen E. Recent advances in the surgical management of necrotizing pancreatitis. Curr Opin Crit Care. 2005. 11:349-52.

100. Leppaniemi A, Johansson K, De Waele JJ. Abdominal compartment syndrome and acute pancreatitis. Acta Clin Belgica. 2007; 62[suppl 1]:131-5

101. Decker G. Abdominal compartment syndrome. J Chir. 2001; 138:270-6.

102. Parr MJA, Olvera Cl. Medical management of abdominal compartment syndrome. In: Ivatury RR, Cheatham ML, Malbrain MLNG, Sugrue M (Editors). Abdominal Compartment Syndrome. Landes Bioscience. 2006. P.232-239.

103. Ivatury RR, Kolkman KA, Johansson K. Management of open abdomen. Acta Clin Belgica. 2007; 62[suppl 1]:206-9.

104. Balogh Z, Moore FA, Goettler CE, Rotondo MF, Schwab CW, Kaplan MJ. Surgical management of the abdominal compartment syndrome. In: Ivatury RR, Cheatham ML, Malbrain MLNG, Sugrue M (Editors). Abdominal Compartment Syndrome. Landes Bioscience. 2006. P. 266-96

105. Sugrue M, D'Amours SK, Kolkman KA. Temporary abdominal closure. Acta Clin Belgica. 2007; 62[suppl. 1]:210-4.

106. Van As AB, Navsaria $P$, Numanoglu A, McCulloch M. Modified sandwich vacuum pack technique for temporary closure of abdominal wounds: an African perspective. Acta Clin Belgica. 2007; 62[suppl. 1]:215-9.

107. Petersson U, Acosta S, Bjorck M. Vacuumassisted wound closure and mesh-mediated traction: a novel combination of two techniques for closure of the open abdomen. Acta Clin Belgica. 2007; 62[suppl. 1]:295

108. Libberecht K, Colpaert SDM, Van Hee R, Jadoul JL, De Clerq S, Sonneville T. New developments in abdominal wall reconstruction after abdominal compartment syndrome decompression. Acta Clin Belgica. 2007; 62[suppl.1]:220-4 